\title{
Uso de indicadores microbiológicos e de fertilidade do solo em áreas de pastagens
}

\section{Soil microbiological, and chemical indicators in pastures}

\author{
Giovana Cristina Maschio Pelágio Vicente ${ }^{1}$; Fabio Fernando de Araujo ${ }^{2 *}$
}

\section{Resumo}

Os indicadores químicos, físicos e biológicos têm sido utilizados com freqüência para indicar mudanças na qualidade do solo. O objetivo desse estudo foi avaliar e correlacionar esses indicadores do solo para que possam serem utilizados na aferição da qualidade atual dos solos sob pastagens na região Oeste Paulista. Foram avaliados treze indicadores em 108 amostras de solos, coletadas em áreas de pastagens estabelecidas há mais de dois anos. O carbono microbiano e o $\mathrm{pH}$ apresentaram os menores coeficientes de variação, dentro dos indicadores biológicos e de fertilidade do solo, respectivamente, enquanto que o teor de fósforo solúvel apresentou a maior variabilidade dentro dos treze indicadores avaliados. Nos solos sob pastagens, avaliados neste estudo, predominaram solos ácidos e com baixos teores de fósforo e potássio. A análise de componentes principais mostrou grande dependência entre as diferentes variáveis analisadas. Os teores de argila apresentaram baixa variabilidade e correlacionaramse significativamente $(\mathrm{p}<0,01) \mathrm{com}$ a CTC e o carbono total do solo. A biomassa microbiana se correlacionou, positivamente, com a maioria das variáveis de fertilidade e microbiológicas do solo, com exceção apenas do teor de potássio no solo e o quociente metabólico, podendo então ser considerada um bom indicador biológico para esses solos.

Palavras-chave: Biomassa microbiana, fertilidade do solo, qualidade do solo

\begin{abstract}
The chemical, physical and biological indicators have been frequently used to indicate changes in soil quality. Thus, the objective of this study was to assess the current state of soils under pastures in the western region of São Paulo using the evaluation and correlation of different microbiological and soil fertility variables. Thirteen quantitative variables were evaluated in 108 soil samples collected in pastures established more than two years. The microbial biomass carbon had the lowest coefficient of variation, while $\mathrm{t}$ the $\mathrm{pH}$ had the lowest coefficient of variation and soluble phosphorus showed the highest variability, within the chemical variables in the soils. In soils under pastures, evaluated in this study, acid soils and low phosphorus and potassium were predominant. The principal component analysis showed a great dependence between different variables. The clay had low variability, showing significant correlation $(\mathrm{p}<0.01)$ with the CEC and total soil carbon. Microbial biomass was correlated positively with most of the variables of fertility and microbiology, which can then be considered a good biological indicator for these soils.
\end{abstract}

Key words: Microbial biomass carbon, soil fertility, soil quality

\footnotetext{
${ }^{1}$ Bioquímica, Divisão de saneamento básico, Universidade do Oeste Paulista, UNOESTE, Presidente Prudente, SP. E-mail: giovana_cris9@yahoo.com.br

${ }^{2}$ Eng $^{\mathrm{o}}$ Agr $^{\mathrm{o}}$, Prof. Dr. da Faculdade de Ciências Agrárias, UNOESTE, Presidente Prudente, SP. E-mail: fabio@unoeste.br

* Autor para correspondência
} 


\section{Introdução}

O Oeste Paulista, área que inclui o Pontal do Paranapanema, é composto por 32 municípios e caracteriza-se por condições climáticas que denotam uma forte concentração pluvial nos meses de primavera/verão associada ao uso do solo predominantemente destinado à pecuária extensiva e ao cultivo de cana-de-açúcar. Os solos predominantes na região, classificados como argissolos, apresentam baixo teor de argila uniforme ao longo do seu perfil, baixa capacidade de retenção de água e podem ser considerados de textura predominantemente arenosa (SÃO PAULO, 1999). O solo como habitat é um sistema heterogêneo, descontínuo e estruturado, formado por micro-habitats, onde células, populações ou comunidades microbianas são encontradas (MOREIRA; SIQUEIRA, 2006). Solos em sistemas de manejo com menor revolvimento, como as pastagens, apresentam melhores condições para o desenvolvimento das populações microbianas na camada superficial do solo (D'ANDREA et al, 2002). Neste contexto, a avaliação dos indicadores microbiológicos e bioquímicos nos ecossistemas pode discriminar alterações na comunidade microbiana do solo decorrentes de atividades antrópicas diversas (MELLONI et al., 2001).

Indicadores relacionados à microbiologia do solo, como a atividade enzimática (BALOTA et al., 2004; DICK; BREAKWELL; TURCO, 1996) e também relacionados à fertilidade do solo como o pH e a disponibilidade de nutrientes (RAIJ et al., 2001) podem contribuir para a melhor compreensão do efeito da interferência antrópica no solo. Atualmente, existe um esforço multidisciplinar para se quantificar diferentes atributos que estão relacionados com a sustentabilidade que são utilizados como indicadores de qualidade do solo.

A matéria orgânica do solo (MOS) interfere nas propriedades físicas, químicas e biológicas do solo, sendo considerada por alguns autores como o mais relevante indicador de qualidade do solo
(BOLINDER et al., 1999). Diretamente relacionado com a MOS, o carbono da biomassa microbiana do solo também é um sensível indicador da qualidade do solo (CARDOSO et al., 2009). A quantificação da biomassa microbiana, respiração basal e suas relações como, por exemplo, quociente metabólico $\left(q \mathrm{CO}_{2}\right)$, tem sido utilizado para estudar os processos de ciclagem e transformação de nutrientes (MALUCHE-BARETTA; KLAUBERG FILHO; AMARANTE, 2006).

$\mathrm{O}$ uso de indicadores dentro da sustentabilidade ambiental é de grande importância na avaliação dos solos, pois permite a adoção antecipada de medidas corretivas ou de controle, além de identificar o que ocorre com o sistema de manejo, contribuindo para aumentar ou diminuir a sustentabilidade do sistema de produção (CHAER; TÓTOLA, 2007). Neste sentido, o objetivo deste trabalho foi avaliar e correlacionar os indicadores microbiológicos, de fertilidade e granulométricos de solos sob pastagem, na região Oeste Paulista.

\section{Material e Métodos}

A área de estudo está situada dentro da zona fisiográfica pertencente à Unidade de Gerenciamento de Recursos Hídricos Pontal do Paranapanema (UGRHI - 22), com $11.838 \mathrm{~km}^{2}$ de superfície, fica localizada entre as coordenadas geográficas de latitudes $21^{\circ} 45^{\prime} \mathrm{S}$ e $22^{\circ} 45^{\prime} \mathrm{S}$ e longitudes $51^{\circ} \mathrm{W}$ e $53^{\circ} \mathrm{W}$, no extremo oeste do Estado de São Paulo. Nesta região foram visitados 28 municípios, onde foram coletadas, em áreas de pastagens estabelecidas há mais de dois anos, 108 amostras de solo, na camada de 0-20 cm, classificados como argissolos de textura média a arenosa. As áreas visitadas, tem recebido com freqüência, adubação de cobertura no verão de acordo com recomendações técnicas para região. A coleta foi realizada com auxílio de trado de rosca, sendo feitas três amostragens por ponto de coleta. Após a homogeneização, aproximadamente 2 $\mathrm{kg}$ do solo coletado foi empacotado e imediatamente enviado ao laboratório, onde foi peneirado (2 mm) 
e homogeneizado. As amostras de solo foram conservadas em sacos plásticos sob refrigeração (5 a $7^{\circ} \mathrm{C}$ ) até o momento das análises, que ocorreram em até sete dias após a coleta.

Antes das analises biológicas, foi calculado, o teor de umidade do solo, obtida por pesagem de sub-amostras antes e depois de secagem em estufa $\left(24 \mathrm{~h}, 110^{\circ} \mathrm{C}\right)$. A capacidade máxima de retenção de água do solo também foi calculada, sendo que para isto uma porção da amostra de solo foi colocada em anel de alumínio de volume conhecido. Os anéis foram colocados em bandejas de alumínio com água durante 24 horas. Após este período, as amostras saturadas foram retiradas e pesadas. As amostras foram então transferidas para a estufa a $110^{\circ} \mathrm{C}$ por 24 horas, e após, retiradas da estufa e pesada, para determinação da massa do solo seco. Pela diferença do solo saturado e seco, em volume conhecido, obteve-se o percentual de porosidade total. Com base na porosidade total e a umidade natural das amostras, foi efetivada a adequação da umidade para $50 \%$ da capacidade máxima de retenção de água no solo. Após esse procedimento foram realizadas as análises biológicas no solo.

A respiração basal e induzida no solo foi avaliada segundo Alef e Nanipieri (1995). Cada amostra foi subdividida em quatro sub-amostras de $50 \mathrm{~g}$ e duas sub-amostras receberam 4,0 mg de glicose $\mathrm{g}$ solo $^{-1}$. Estas foram homogeneizadas e mantidas dentro de frascos herméticos. Sobre a superfície do solo, em cada frasco foi colocado um becker de $50 \mathrm{ml}$ contendo $40 \mathrm{~mL}$ de solução de $\mathrm{NaOH} 0,5 \mathrm{~mol} \mathrm{~L}^{-1}$. Os frascos com e sem adição de glicose ficaram incubados pelo período de 72 horas. Para avaliar a retenção de $\mathrm{CO}_{2}$ na solução, utilizou-se o método condutimétrico (RODELLA; SABOYA, 1999) com leituras de condutividade na solução de $\mathrm{NaOH}$ a cada 24 horas, empregando-se um condutivímetro HI99301 (Hanna instruments). A quantidade de $\mathrm{CO}_{2}$ produzida pela respiração induzida (com adição de glicose) e pela respiração basal (sub-amostras de solo que não receberam glicose) foi calculada utilizando-se fórmula definida por Rodella e Saboya
(1999) e os resultados foram expressos em mg de $\mathrm{C}-\mathrm{CO}_{2} \mathrm{~g}^{-1} \mathrm{~h}^{-1}$.

A partir dos dados da quantidade de $\mathrm{CO}_{2}$ produzido pela respiração induzida, foi calculada a biomassa microbiana, utilizando-se a fórmula proposta por Harden et al. (1993), onde: C-mic $(\mu \mathrm{g}$ de $\mathrm{C}$ g de solo $\left.^{-1}\right)=\left(\mu \mathrm{L}\right.$ de $\mathrm{C}-\mathrm{CO}_{2} \mathrm{~g}^{-1}$ de solo $\left.\mathrm{h}^{-1}\right)$ x 30. O quociente metabólico $\left(q \mathrm{CO}_{2}\right)$ foi obtido a partir da relação entre a respiração basal do solo e a biomassa microbiana no solo. A atividade da enzima desidrogenase foi estimada segundo Van Os e Ginkel (2001). Após o peneiramento ( $\Phi-2 \mathrm{~mm})$, alíquotas de $5 \mathrm{~g}$ de solo, de cada amostra, foram saturadas com $2 \mathrm{~mL}$ de solução de TTC $(2,3,5-$ cloreto de trifeniltetrazólio) a $1 \%$ em tampão tris $0,1 \mathrm{M}(\mathrm{pH} 7,6)$ e $1 \mathrm{ml}$ de glicose $(0,1 \%)$. Seis subamostras de cada amostra de solo, coletadas em cada localidade foram utilizadas no ensaio, sendo três com adição de TTC e três sem adição (controle). As amostras foram misturadas em agitador tipo VORTEX e incubadas em tubo de ensaio a $30^{\circ} \mathrm{C}$, por $18 \mathrm{~h}$. Após incubação, $9 \mathrm{~mL}$ de metanol foram adicionados a cada tubo e o conteúdo foi agitado manualmente e filtrado em filtro tipo Whatman $\mathrm{N}^{\mathrm{o}}$ 1. A intensidade da cor vermelha no filtrado (formação de trifeniltetrazólio formazan - TTF) foi determinada espectrofotometricamente a $530 \mathrm{~nm}$.

A análise textural do solo foi efetuada pelo método da pipeta (DAY, 1965), após dispersão da amostra com NaOH $1 \mathrm{~mol} \mathrm{~L}^{-1-}$ e agitação a 40 rpm) por 12 a 16 horas. As análises de fertilidade do solo ( $\mathrm{pH}$, cálcio, magnésio, potássio e fósforo), foram realizadas de acordo com Raij et al. (2001). O carbono orgânico no solo foi determinado por meio de oxidação da matéria orgânica com dicromato de potássio a 0,2 $\mathrm{M}$ em meio ácido (EMBRAPA, 1997).

Os resultados obtidos foram analisados estatisticamente pelo programa Sigmaplot, empregando-se a correlação de Pearson. Avaliouse também a distribuição de freqüência dos dados que foram apresentados na forma de histograma. 
A análise de componentes principais (ACP) foi calculada pelo programa ADE-4 (THIOULOUSE et al., 1997), utilizando uma matriz com 108 pontos $\times$ 13 variáveis microbiológicas, física e de fertilidade dos solos.

\section{Resultados e Discussão}

Na tabela 1, os valores médios de $\mathrm{pH}$, saturação por bases e de alguns nutrientes como o fósforo (P) e potássio $(\mathrm{K})$, caracterizam os solos da região como ácidos e de baixa disponibilidade de nutrientes para as plantas, tomando como referencial o recomendado por Raij et al. (2001). O teor médio de argila encontrado nos solos analisados caracteriza os mesmos como de textura média a arenosa (EMBRAPA, 1999). O pH foi a variável que apresentou o menor coeficiente de variação no conjunto de amostras avaliadas, ratificando o encontrado por Chaves et al. (2004) em estudo semelhante em solos aluviais. Enquanto que nas variáveis biológicas observou-se que a biomassa microbiana proporcionou o menor coeficiente de variação, apresentando média de $345 \mu \mathrm{g}$ de $\mathrm{C} \mathrm{g}^{-1}$ de solo, valor próximo ao encontrado por Oliveira, Mendes e Vivaldi (2001) e Souza et al. (2006) em análise semelhantes feitas em Latossolos cultivados com pastagens. Por outro lado, a atividade enzimática apresentou o maior coeficiente de variação entre as avaliações biológicas.

Tabela 1. Valores da média, desvio-padrão, erro padrão e coeficientes de variação obtidos na análise de 13 variáveis químicas, físicas e microbiológicas em 108 amostras de solos sob pastagens.

\begin{tabular}{|c|c|c|c|c|}
\hline Variáveis & Média & Desvio padrão & Erro padrão $( \pm)$ & $\begin{array}{c}\text { Coef. de variação } \\
(\%)\end{array}$ \\
\hline Teor de argila $\left(\mathrm{g} \mathrm{kg}^{-1}\right)$ & 111,01 & 44,12 & 4,24 & 39,7 \\
\hline Respiração basal (mg C-CO $\left.{ }_{2} \mathrm{~g}^{-1} \mathrm{~h}^{-1}\right)$ & 9,52 & 5,78 & 0,556 & 60,7 \\
\hline Biomassa microbiana $\left(\mu \mathrm{g} \mathrm{C} \mathrm{g}^{-1}\right)$ & 345,46 & 136,93 & 13,17 & 39,6 \\
\hline Ativ. da desidrogenase ( $\mu \mathrm{g}_{\left.\text {TTF } \mathrm{g}^{-1}\right)}$ & 85 & 0,078 & 0,008 & 91,8 \\
\hline $\mathrm{qCO}_{2}\left(\mathrm{mg} \mathrm{C}-\mathrm{CO}_{2} \mu \mathrm{g} \mathrm{C} \mathrm{h}^{-1}\right)$ & 0,028 & 0,013 & 0,001 & 46,4 \\
\hline $\mathrm{pH}\left(\mathrm{CaCl}_{2}\right)$ & 4,96 & 0,594 & 0,057 & 12,0 \\
\hline C-organico $\left(\mathrm{g} \mathrm{dm}^{-3}\right)$ & 8,92 & 5,237 & 0,504 & 58,7 \\
\hline $\mathrm{Ca}\left(\mathrm{mmol} \mathrm{dm}{ }^{-3}\right)$ & 10,08 & 10,65 & 1,02 & 105,7 \\
\hline $\operatorname{Mg}\left(\mathrm{mmol} \mathrm{dm}{ }^{-3}\right)$ & 5,43 & 8,34 & 0,802 & 153,7 \\
\hline $\mathrm{K}\left(\mathrm{mmol} \mathrm{dm}{ }^{-3}\right)$ & 1,53 & 1,04 & 0,101 & 68,6 \\
\hline $\mathrm{P}\left(\mathrm{mg} \mathrm{dm} \mathrm{m}^{-3}\right)$ & 13,96 & 24,85 & 2,39 & 178,0 \\
\hline $\mathrm{CTC}\left(\mathrm{mmol} \mathrm{dm}^{-3}\right)$ & 39,42 & 20,57 & 1,97 & 52,2 \\
\hline Saturação por bases (\%) & 39,21 & 17,67 & 1,70 & 45,1 \\
\hline
\end{tabular}

Fonte: Elaboração dos autores.

Nos histogramas apresentados nas Figuras 1 e 2, observou-se que na avaliação da biomassa microbiana foi onde se encontrou o modelo mais adequado para o ajuste simétrico ou normal. A assimetria à esquerda, encontrada na maioria das variáveis de fertilidade do solo analisadas, revela a discrepância no conjunto de dados e que segundo Chaves et al. (2004) nestes casos não se recomenda a utilização de suas médias para inferir sobre a variabilidade das amostras. Neste enfoque, pode ser verificado que na variável $\mathrm{pH}$ aproximadamente $90 \%$ das amostras estão concentradas nas quatro primeiras classes, com valores de 4,0 a 5,6 e na variável $\mathrm{P}$ disponível cerca de $85 \%$ das amostras na classe mais baixa a esquerda. Com relação ao P disponível, Mélem Júnior et al. (2008) também encontraram baixos valores de fósforo em 1343 amostras de solos com a freqüência acima de $80 \%$ na primeira classe à esquerda do histograma, revelando a necessidade de adubação nesses solos. 
Figura 1. Distribuição de frequência dos resultados de teor de argila, análises microbiológicas (biomassa microbiana, respiração e atividade enzimática) e de fertilidade (pH, P, K e carbono orgânico) em 108 amostras de solos, sob pastagens, na região Oeste Paulista.
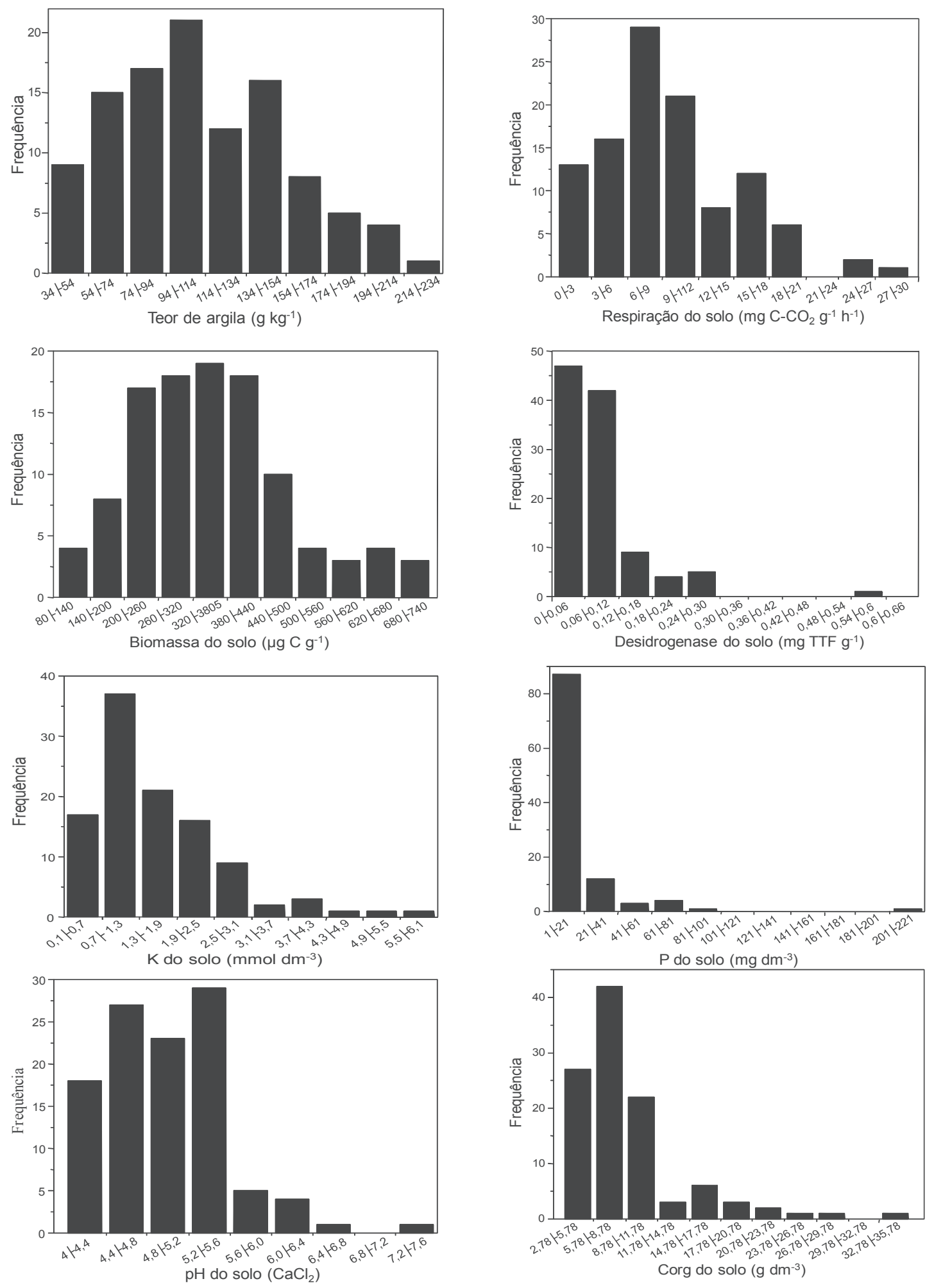

Fonte: Elaboração dos autores. 
Figura 2. Distribuição de frequência dos resultados de coeficiente metabólico $(q \mathrm{CO} 2)$ em 108 amostras de solos, sob pastagens, na região Oeste Paulista.

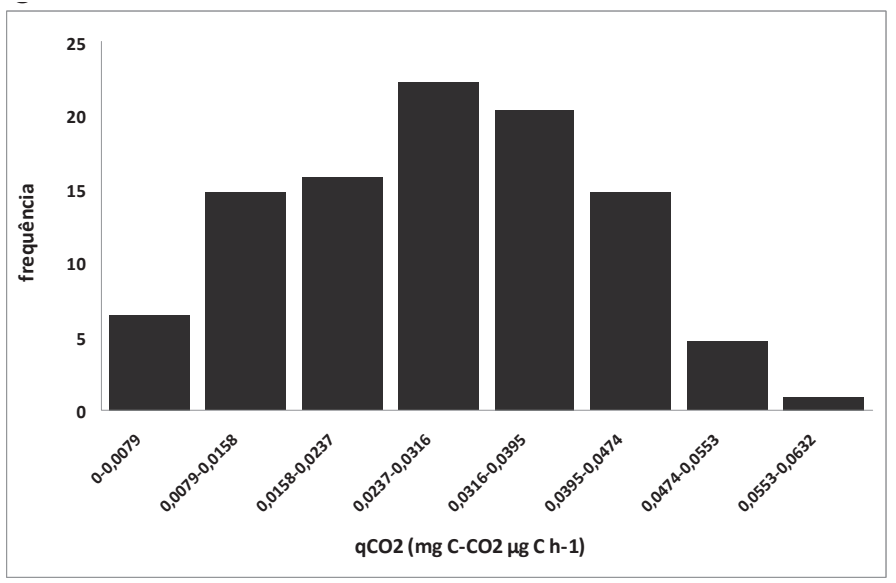

Fonte: Elaboração dos autores.

Na tabela 2 pode ser destacado que a correlação da biomassa com a maioria das variáveis apresentou resultados mais significativos $(p<0,01)$, apesar de que para a maioria dos dados, essas foram abaixo de 0,32; já os teores de potássio não se correlacionaram com nenhuma variável biológica ou física. Foram encontradas correlações significativas $(p<0,01)$ do teor de argila com a CTC e com o carbono orgânico, fato este que confirma o que foi relatado por Nogueira Junior (2000) sobre a correlação dessas variáveis em solos de textura arenosa, apesar desses autores terem encontrados valores de correlações mais elevados.

Tabela 2. Correlação de Pearson (r) entre diferentes variáveis biológicas, físicas e químicas em amostras de solo na região Oeste Paulista.

\begin{tabular}{lcccc}
\hline Variáveis & Biomassa & Respiração & Desidrogenase & Teor de argila \\
\hline Biomassa & - & $0,64^{* *}$ & $0,23^{*}$ & $0,19^{*}$ \\
Respiração & $0,64^{* *}$ & - & $0,21^{*}$ & $0,15^{\mathrm{NS}}$ \\
Desidrogenase & $0,23^{*}$ & $0,21^{*}$ & - & $-0,04^{\mathrm{NS}}$ \\
$\mathrm{qCO}_{2}$ & $-0,03^{\mathrm{NS}}$ & 0,69 & $0,06^{\mathrm{NS}}$ & $-0,01^{\mathrm{NS}}$ \\
$\mathrm{pH}\left(\mathrm{CaCl}_{2}\right)$ & $0,19^{*}$ & $0,19^{*}$ & $0,41^{* *}$ & $-0,06^{\mathrm{NS}}$ \\
$\mathrm{C}-$ orgânico & $0,21^{*}$ & $0,22^{*}$ & $0,10^{\mathrm{NS}}$ & $0,52^{* *}$ \\
Teor de argila & $0,19^{*}$ & $0,15^{\mathrm{NS}}$ & $0,04^{\mathrm{NS}}$ & - \\
$\mathrm{Ca}$ & $0,32^{* *}$ & $0,14^{\mathrm{NS}}$ & $0,51^{* *}$ & $-0,08^{\mathrm{NS}}$ \\
$\mathrm{Mg}$ & $0,26^{* *}$ & $0,11^{\mathrm{NS}}$ & $0,62^{* *}$ & $0,02^{\mathrm{NS}}$ \\
$\mathrm{K}$ & $0,14^{\mathrm{NS}}$ & $0,16^{\mathrm{NS}}$ & $0,05^{\mathrm{NS}}$ & $-0,01^{\mathrm{NS}}$ \\
$\mathrm{P}$ & $0,27^{* *}$ & $0,29^{* *}$ & $0,08^{\mathrm{NS}}$ & $0,23^{*}$ \\
$\mathrm{CTC}$ & $0,30^{* *}$ & $0,32^{* *}$ & $0,28^{* *}$ & $0,35^{* *}$ \\
Saturação por bases $(\%)$ & $0,32^{* *}$ & $0,23^{*}$ & $0,42^{* *}$ & $-0,02^{\mathrm{NS}}$ \\
\hline
\end{tabular}

*Significativo $(\mathrm{P}<0,05)$; ** Significativo $(\mathrm{P}<0,01)$; Não significativo ( $\left.{ }^{\mathrm{NS}}\right)$.

Fonte: Elaboração dos autores. 
A análise dos componentes principais (ACP) revelou que a variância total dos dados foi explicada em 63,3\% nos três primeiros componentes (Tabela 3). Alguns estudos consideram os três primeiros componentes como mais importantes para avaliação da variabilidade do conjunto de dados obtidos (BORUVKA; VACEK; JEHLICKA, 2005). Na avaliação de dados ambientais o valor da variância encontrado é considerado satisfatório, pois segundo Costa (2009), que desenvolveu análises semelhantes a este estudo, a variância de $34 \%$ encontrada nos eixos 1 e 2 é considerada adequada em razão do elevado número de fatores que podem contribuir para uma determinada observação. Pelo agrupamento das amostras de solo dentro de apenas um quadrante pode ser observada a relação próxima entre elas indicando relativa homogeneidade na sua origem geológica (Figura 3).

Tabela 3. Correlação das variáveis física, microbiológicas e de fertilidade, analisadas em amostras de solos, com os três primeiros componentes da análise multivariada $(\mathrm{ACP})^{1}$.

\begin{tabular}{lccc}
\hline Variáveis & Componente 1 & Componente 2 & Componente 3 \\
\hline Teor de argila & $-0,1006$ & $-0,3821$ & 0,2436 \\
Respiração & $-0,2328$ & $-0,3015$ & $-0,5713$ \\
Biomassa & $-0,2548$ & $-0,1261$ & $-0,2157$ \\
Desidrogenase. & $-0,2727$ & 0,2788 & $-0,1498$ \\
$\mathrm{qCO}_{2}$ & $-0,0561$ & $-0,2412$ & $\mathbf{0 , 6 1 1 1 * * *}$ \\
$\mathrm{pH}\left(\mathrm{CaCl}_{2}\right)$ & $-0,3286$ & 0,1433 & 0,0080 \\
$\mathrm{C}-$ Orgânico & $-0,2220$ & $\mathbf{- 0 , 3 8 9 9 * *}$ & 0,2852 \\
$\mathrm{Ca}$ & $-0,3489$ & 0,3412 & 0,0202 \\
$\mathrm{Mg}$ & $-0,3124$ & 0,3856 & $-0,0264$ \\
$\mathrm{~K}$ & $-0,2252$ & $-0,0981$ & 0,1061 \\
$\mathrm{P}$ & $-0,2840$ & $-0,2967$ & 0,1842 \\
$\mathrm{CTC}$ & $-0,3599$ & $-0,2218$ & 0,1995 \\
Saturação por bases & $\mathbf{- 0 , 3 9 4 7 *}$ & 0,1632 & 0,0653 \\
Autovalor & 4,48 & 2,15 & 1,58 \\
Variância $(\%)$ & 34,48 & 16,59 & 12,20 \\
\hline
\end{tabular}

${ }^{1}$ Valores em negrito se referem a variável com o maior coeficiente associado ao *primeiro, **segundo e ***terceiro eixo da avaliação de componentes principais.

Fonte: Elaboração dos autores.

A maioria das variáveis, apresentaram maior correlação com o Componente 1 (Tabela 3) e neste componente todas as variáveis se correlacionaram negativamente indicando que o aumento no valor de uma determinada variável influencia no aumento da outra variável. Isto aponta que as variáveis estão muito próximas e podem explicar a mesma informação, como também que o componente agrupou resultados de solos qualitativamente semelhantes (LEONARDO, 2003). Considerando a avaliação simultânea dos componentes 1 e 2, que representam cerca de $51 \%$ da variância, pode ser observado que as variáveis que mais se correlacionaram com escores elevados nos dois primeiros componentes foram: respiração, atividade enzimática da desidrogenase, carbono orgânico, cálcio, magnésio, fósforo e capacidade de troca catiônica. Os escores encontrados na maioria das variáveis dentro de cada componente foram baixos, com exceção do quociente metabólico no componente 3 .

Em avaliação da degradação de um Latossolo, Ruivo, Barros e Schaefer (2006) afirmaram que a biomassa microbiana apresenta-se como um indicador sensível a pequenas mudanças no ambiente e capaz de indicar o estágio de 
recuperação ou degradação do solo. Cardoso et al. (2009) também concluíram que o emprego da avaliação da biomassa microbiana é o mais indicado em avaliação de pastagens cultivadas por vários anos, pois foi encontrado que com o passar dos anos a tendência é de aumento nos valores da biomassa microbiana no solo, atribuídos ao intenso desenvolvimento e ciclagem do sistema radicular das gramíneas forrageiras, na camada superior do solo.
Pelos resultados encontrados neste trabalho pode-se também sugerir que no ecossistema avaliado, esta variável apresentou baixa variabilidade e correlação significativa com a maioria das outras variáveis analisadas. Souza et al. (2006) concluíram que a biomassa microbiana e a fração leve do carbono podem ser considerados os melhores indicadores da qualidade do solo e do declínio do carbono orgânico total em curto prazo.

Figura 3. Análise de componentes principais para os atributos microbiológicos e químicos obtidos nas amostras de solos de 28 municípios da região Oeste Paulista.

Eixo $2(16.57 \%)$

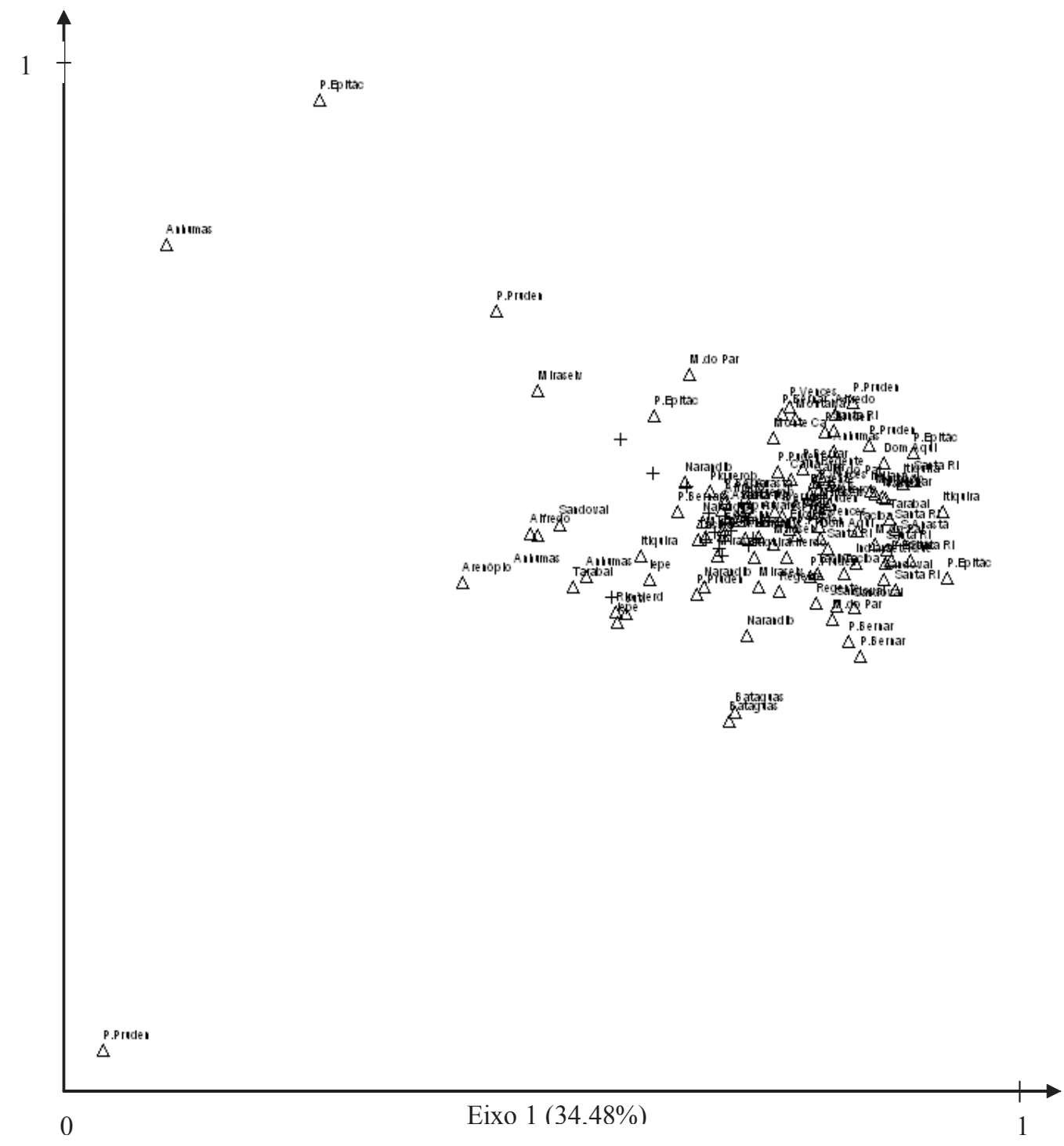

Fonte: Elaboração dos autores. 
No presente trabalho, foi obtido que o carbono microbiano correspondeu a $3,9 \%$ do carbono orgânico total indicando, de acordo com GamaRodrigues (1999), eficiência dos microrganismos em imobilizar carbono na sua biomassa. Os valores baixos de $\mathrm{qCO}_{2}$ e a distribuição com tendência de curva normal (Figura 2), encontrados neste trabalho, também reforçam a tese de que o carbono está sendo utilizado de forma mais eficiente pela microbiota do solo, pois os valores mais elevados neste parâmetro pode ser indicativo de condições ambientais mais estressantes com perdas de carbono do solo (ANDERSON; DOMSCH, 1993).

A avaliação da biomassa microbiana pode contribuir positivamente na avaliação dos impactos no uso dos solos avaliados neste trabalho. Enquanto que a análise multivariada (ACP) indicou pelos valores de correlação das variáveis, encontrados em dois componentes, que a melhoria de um determinado atributo do solo pode refletir diretamente na melhoria de outros. O conhecimento da variabilidade dentro dos atributos avaliados é importante, principalmente para definir o manejo mais adequado a ser utilizado na área em estudo.

\section{Conclusões}

Nos solos sob pastagens, avaliados neste estudo, as maiores variabilidades foram verificadas para cálcio, magnésio e fósforo e as menores foram encontradas para o $\mathrm{pH}$, teor de argila e biomassa microbiana.

A biomassa microbiana se correlacionou, positivamente, com a maioria das variáveis de fertilidade e microbiológicas, apesar de que, em muitos casos foi considerada baixa.

\section{Referências}

ALEF, K.; NANNIPIERI, P. Methods in applied soil microbiology and biochemistry. London: Academic Press, 1995. 576 p.
ANDERSON, J. P. E.; DOMSCH, K. H. The metabolic quotient $\left(q \mathrm{CO}_{2}\right)$ as a specific activity parameter to asses the effects of environmental conditions, such as $\mathrm{pH}$, onthe microbial biomass of forest soils. Soil Biology and Biochemistry, Oxford, v. 25, n. 3, p. 393-395, 1993.

BALOTA, E. L.; KANASHIRO, M.; COLOZZI FILHO, A.; ANDRADE, D. S.; DICK, R. P. Soil enzyme activities under long-term tillage and crop rotation systems in subtropical agro-ecosystems. Brazilian Journal of Microbiology, São Paulo, v. 35, n. 4, p. 300-306, 2004.

BOLINDER, M. A.; ANGERS, D. A.; GREGORICH, E. G.; CARTER, M. R. The response of soil quality indicators to conservation management. Canadian Journal of Soil Science, Ottawa, v. 79, n. 1, p. 37-45, 1999.

BORUVKA, L.; VACEK, O.; JEHLICKA, J. Principal component analysis as a tool to indicate the origin of potentially toxic elements in soil. Geoderma, Amsterdam, v. 128, n. 3-4, p. 289-300, 2005.

CARDOSO, E. L.; SILVA, M. L. N.; MOREIRA, F. M. S.; CURI, N. Atributos biológicos indicadores da qualidade do solo em pastagem cultivada e nativa no Pantanal. Pesquisa Agropecuária Brasileira, Brasília, v. 44, n. 6, p. 631-637, 2009.

CHAER, G. M.; TÓTOLA, M. R. Impacto do manejo de resíduos orgânicos durante a reforma de plantios de eucalipto sobre indicadores de qualidade do solo. Revista Brasileira de Ciência do Solo, Viçosa, MG, v. 31, n. 6, p. 1381-1396, 2007.

CHAVES, L. H. G.; TITO, G. A.; CHAVES, I. B.; LUNA, J. G.; SILVA, P. C. M. Propriedades químicas do solo aluvial da ilha de Assunção - Cabrobó (Pernambuco). Revista Brasileira de Ciência do Solo, Viçosa, MG, v. 28, n. 3, p. 431-437, 2004.

COSTA, C. F. Solos e outros fatores ambientais associados à diversidade fenotípica de macaubais no Estado de São Paulo. Campinas, 2009. Dissertação (Mestrado em Agronomia) - Instituto Agronômico de Campinas, Campinas.

D'ANDREA, A. F.; SILVA, M. L. N.; CURI, N.; SIQUEIRA, J. O.; CARNEIRO, M. A. C. Atributos biológicos indicadores da qualidade do solo em sistemas de manejo na Região do Cerrado no sul do Estado de Goiás. Revista Brasileira de Ciência do Solo, Viçosa, MG, v. 26, n. 5, p. 913-923, 2002.

DAY, P. R. Particle fraction and particle fractionation and particle-size analysis. In: BLACK, C. A. (Ed.). Methods of soil analysis. Madison, American Society of Agronomy, 1965. v. 1, p. 545-566. 
DICK, R. P.; BREAKWELL, D. P.; TURCO, R. F. Soil enzyme activities and biodiversity measurements as integrative microbiological indicators. In: DORAN, J. W.; JONES, A. J. (Ed.). Methods for assessing soil quality. Madison: Soil Science Society of America, 1996. p. 247-272.

\section{EMPRESA BRASILEIRA DE PESQUISA} AGROPECUÁRIA - EMBRAPA. Centro Nacional de Pesquisa de Solos. Manual de métodos de análise de solo. Rio de Janeiro, 1997. 212 p. (Embrapa-CNPS. Documento, 1).

Sistema brasileiro de classificação de solos. Brasília: Embrapa-SPI, Embrapa-CNPS, 1999. 412 p.

GAMA-RODRIGUES, E. F. Biomassa microbiana e ciclagem de nutrientes. In: SANTOS, G. A.; CAMARGO, F. A. O. (Ed.). Fundamentos da matéria orgânica do solo-ecossistemas tropicais e subtropicais. Porto Alegre: Gênesis, 1999. p. 227-244.

HARDEN, T.; JOERGENSON, R. G.; MEYER, B. WOLTERS, V. Soil microbial biomass estimated by fumigation-extraction and substrate-induced respiration in two pesticide-treated soils. Soil Biology and Biochemistry, Oxford, v. 25, n. 6, p. 679-683, 1993.

LEONARDO, H. C. L. Indicadores de qualidade de solo e água para a avaliação do uso sustentável da microbacia hidrográfica do Rio Passo Cue, região oeste do Estado do Paraná. 2003. Dissertação (Mestrado em agronomia). Escola Superior de Agricultura Luiz de Queiroz, Piracicaba.

MALUCHE-BARETTA, C. R. D.; KLAUBERG FILHO, O.; AMARANTE, C. V. T. Análise multivariada de atributos do solo em sistemas convencional e orgânico de produção de maças. Pesquisa Agropecuária Brasileira, Brasília, v. 41, n. 10, p. 1531-1539, 2006.

MELÉM JÚNIOR, N. J.; FONSECA, I. C. de B.; BRITO, O. R.; DECAËNS, T.; CARNEIRO, M. M.; MATOS, M. de F. A.; GUEDES, M. C.; QUEIROZ, J. A. L. de; BARROSO, K. O. Análise de componentes principais para avaliação de resultados analíticos da fertilidade de solos do Amapá. Semina. Ciências Agrárias, Londrina, v. 29, n. 3, p. 499-506, 2008.

MELLONI, R.; PEREIRA, E. G.; TRANNIN, I. C. B.; SANTOS, D. R. dos; MOREIRA, F. M. S.; SIQUEIRA, J. O. Características biológicas de solos sob mata ciliar e campo cerrado no sul de Minas Gerais. Ciência e Agrotecnologia, Lavras, v. 25, n. 1, p. 7-13, 2001.
MOREIRA, S. M. F.; SIQUEIRA, O. J. Microbiologia e bioquímica do solo. 2. ed. Lavras: UFLA, 2006.

NOGUEIRA JUNIOR, L. R. Caracterização de solos degradados pela atividade agrícola e alterações biológicas após reflorestamentos com diferentes associações de espécies da mata atlântica. 2000. Dissertação (Mestrado em Agronomia) - Escola Superior de Agricultura Luiz de Queiroz, Piracicaba.

OLIVEIRA, J. R.; MENDES, I. C.; VIVALDI, L. Carbono da biomassa microbiana em solos de cerrado sob vegetação nativa e sob cultivo:avaliação dos métodos fumigação-incubação e fumigação-extração. Revista Brasileira de Ciência do Solo, Viçosa, MG, v. 25, n. 5, p. 863-871, 2001.

RAIJ, B. V.; ANDRADE, J. C.; CANTARELlA, H.; QUAGGIO, J. A. Análise química para avaliação da fertilidade de solos tropicais. Campinas: Instituto Agronômico, 2001. 285 p.

RODELlA, A. A.; SABOYA, L. V. Calibration for conductimetric determination of carbon dioxide. Soil Biology and Biochemistry, Oxford, v. 31, n. 14, p. 20592060, 1999.

RUIVO, M. L. P.; BARROS, N. F.; SCHAEFER, C. E. G. R. Relações da biomassa microbiana do solo com características químicas de frações orgânicas e minerais do solo após exploração mineral na Amazônia Oriental. Boletim do Museu Paraense Emílio Goeldi, Belém, v. 1, n. 2, p. 121-131, 2006.

SÃO PAULO (Estado). Zoneamento ecológicoeconômico do pontal do paranapanema. São Paulo: Secretaria de estado do meio ambiente, 1999. 111 p.

SOUZA, E. D.; CARNEIRO M. A. C.; PAULINO, H. B.; SILVA, C. A.; BUZETTI, S. Frações do carbono orgânico, biomassa e atividade microbiana em um Latossolo Vermelho sob Cerrado submetido a diferentes sistemas de manejos e usos do solo. Acta Scientiarum. Agronomy, Maringá, v. 28, n. 3, p. 323-329, 2006.

THIOUlOUSE, J.; CHESSEL, D.; DOLÉDEC, S.; OLIVIER, J. M. ADE-4: a multivariate analysis and graphical display software. Statistics and computing, Paris, v. 7, n. 1, p. 75-83, 1997.

VAN OS, G. J.; VAN GINKEL, J. H. Suppression of Pythium root rot in bulbous Iris in relation to biomass and activity of the soil microflora. Soil Biology \& Biochemistry, London, v. 33, n. 11, p. 1447-1454, set. 2001. 